\title{
Valores organizacionais e qualidade de serviço em instituições de educação superior: uma perspectiva brasileira
}

\author{
Organizational values and quality \\ of service in higher education \\ institutions: a brazilian perspective
}

\author{
ALEXEY CARVALHO* \\ LISANDRO JOSÉ ALVARADO PEÑA** \\ ALESSANDRO MARCO ROSINI***
}

\section{RESUMO}

Este artigo apresenta resultados preliminares de um estudo realizado no Brasil, parte de uma pesquisa mais abrangente envolvendo Instituições de Educação Superior (IES) de países da América Latina e do Caribe. Tem como objetivo analisar os valores organizacionais presentes na atuação do pessoal técnico-administrativo, como determinantes na qualidade do serviço prestado em IES. Para isso, se buscou compreender os principais aspectos da cultura organizacional nas IES; entender os fatores que influenciam a qualidade de serviços nessas IES; e contribuir para a formulação de estratégias que auxiliem a introjeção dos valores organizacionais e promovam melhoria da qualidade dos serviços. Como método de pesquisa, foram realizados pesquisas bibliográficas e um estudo de campo com estudantes, professores e funcionários técnico-administrativos de uma IES brasileira, que buscou entender as percepções dos pesquisados acerca de quatro dimensões que envolvem a qualidade do serviço: o serviço em si; as relações humanas; as atitudes e a responsabilidade.

* Universidade Estadual de Campinas (UNICAMP). alexey.carvalho@gmail.com

** REOALCEI, México. lisandroinvestigacion@gmail.com

*** ORCID iD http://orcid.org/0000-0002-5150-8483. UNIAN, UNIVAG. alessandro.rossini@yahoo.com 
Os resultados obtidos, indicam que a percepção dos estudantes quanto a prestação de serviços por parte dos funcionários técnico-administrativos é bem diferente da percepção dos professores, assim como, também diverge da visão do próprio funcionário acerca do trabalho que realiza.

Palavras-chave: Educação Superior. Qualidade em Serviço. Cultura Organizacional. Valores Organizacionais. Práticas de gestão.

\section{RESUME}

This paper presents preliminary results from a study conducted in Brazil, part of a broader research involving Higher Education Institutions (HEIs) in Latin American and Caribbean countries. It aims to analyze the organizational values present in the performance of technical and administrative staff, as determinants in the quality of service provided in HEI. For this, we sought to understand the main aspects of organizational culture in HEIs; understand the factors that influence the quality of services in these HEIs; and contribute to the formulation of strategies that help the introjection of organizational values and promote the improvement of service quality. As a research method, we conducted bibliographic research and a field study with students, teachers and technical-administrative staff of a Brazilian HEI, which sought to understand the perceptions of respondents about four dimensions that involve the quality of service: the service itself. ; human relations; attitudes and responsibility. The results indicate that the perception of students regarding the provision of services by technical and administrative staff is quite different from the perception of teachers, as well as diverging from the employee's own view of the work they perform.

Keywords: Higher Education. Quality in service. Organizational culture. Organizational Values. Management practices.

\section{INTRODUÇÃO}

A busca pela qualidade é cada vez mais uma constante para organizações das mais diversas áreas, sejam públicas, privadas ou do terceiro setor. Na Educação Superior brasileira, o cenário competitivo entre as Instituições de Educação Superior (IES) privadas tem se agravado ao longo do tempo, decorrente da grande expansão ocorrida até 2012 e mais recentemente com o aumento de fusões 
e aquisições, capitaneada pelos dos grandes grupos privados de Educação. Nesse cenário, essas IES têm se preocupado, além da qualidade do ensino ofertado, que por sua vez é avaliada pelos órgãos regulatórios ligados ao Ministério da Educação (MEC), com os serviços administrativos ofertados pelas IES, uma vez que podem influenciar na escolha do futuro estudante. Apesar de estarem fora desse contexto de competitivo, as IES públicas também devem zelar pelos serviços prestados em conformidade com seus regimentos e regulamentos, visando o adequado atendimento às demandas dos estudantes e cidadãos.

Este artigo apresenta resultados preliminares de um estudo realizado no Brasil, que é integrante de um estudo mais abrangente envolvendo IES Brasileiras, Colombianas, Mexicanas e Venezuelanas, dentre outras convidadas a participar da América Latina e do Caribe, em que são investigados, dentre os diversos fatores que influenciam a qualidade dos serviços prestados, a influência da cultura organizacional, em especial dos valores organizacionais na atuação do pessoal técnico-administrativo das IES. Longe de uma discussão sobre o estudante como cliente, enquanto gestão, os aspectos estudados da qualidade serão abordados do ponto de vista do usuário de um serviço, podendo nesse caso ser aplicado às IES públicas e às IES privadas, da mesma forma.

Para a realização do estudo partiu-se de alguns indícios, levantados nas pesquisas de Alvarado Peña (2010; 2011), o primeiro é de que os valores éticos são uma determinante no comportamento e nas ações do pessoal técnico-administrativo e, portanto, no serviço que é oferecido aos professores. No que tange aos estudantes, um fator determinante para a qualidade é a resolução em tempo dos serviços solicitados. Em ambos os públicos se verificou, ainda, que a solidariedade, em constância com o ambiente universitário, é um valor relevante e pode influenciar as relações interpessoais e a percepção do serviço prestado.

Diante do exposto, este trabalho tem como objetivo analisar os valores organizacionais presentes na atuação do pessoal técnico-administrativo, como determinantes na qualidade do serviço prestado ao estudante e ao professor em IES, verificando os principais aspectos da cultura organizacional nas IES e buscando entender os 
fatores que influenciam a qualidade de serviços nas IES. Com isso será possível às IES obter subsídios que auxiliem na elaboração de estratégias voltadas à introjeção dos valores organizacionais, se for o caso, e promovam melhoria da qualidade dos serviços ofertados.

\section{REFERENCIAL TEÓRICo}

A educação de forma geral tem sido influenciada pelo fenômeno da globalização, que se caracteriza pela consolidação de um sistema econômico mundial, que provoca impactos em toda a sociedade, com a adoção de políticas transnacionais e relações de interdependência que ultrapassam as barreiras das nações.

A sociedade contemporânea está cada vez mais se organizando em um novo formato, o de redes, nesta nova forma de organização as redes locais se interconectam com outras redes e formam redes globais de capital, bens, serviços, comunicação, informação, ciência e tecnologia, que transcendem as fronteiras das nações e intensificam a globalização, como lembram Castells e Cardoso (2005). Essas constatações reforçam dois pontos presentes neste trabalho: 1) o envolvimento de pesquisadores de vários países, por meio de redes de pesquisa e colaboração; e 2) a necessidade cada vez maior de se inserir as IES dentro de critérios de análise do mundo corporativo.

Da mesma forma, é necessário um cuidado especial, visto que todas as discussões que cercam a Educação Superior, tornam-se mais complexas e interdependentes dos fatores e varáveis que envolvem um contexto mundial. Um dos pontos divergentes e cerne de outras discussões está na oferta da Educação Superior como serviço, em oposição à definição de bem público, direito social e dever do Estado, defendido por Dias (2010). Cabe ressaltar que não há uma incompatibilidade de se tratar da qualidade em serviço nas IES com os demais aspectos que envolvem a Educação Superior, uma vez que as questões relativas ao ensino, pesquisa e extensão, já são tratadas pelos órgãos regulatórios.

De acordo com Freitas (1991) apesar de as discussões sobre a cultura organizacional estarem presentes na literatura há algum tempo, ganharam força a partir da década de 1980, quando em 1983 as revistas Administrative Seience Quarterly e Organizational Dynamics dedicaram edições especiais ao assunto. 
Fazendo uma analogia ao funcionamento dos computadores e sua programação, Hofstede (1991) coloca a cultura como sendo o software da mente, assim, a programação coletiva da mente pode distinguir um grupo de indivíduos de outro, muitas vezes por regras sociais não escritas, podendo se manifestar por meio de símbolos, rituais, práticas e valores, que por sua vez influenciam o comportamento desses indivíduos.

A fundamentação acerca da qualidade em serviço abordadas, parte das definições de Vargas e Aldana (2007) e Camarasa (2004), estudadas por Alvarado Peña (2010), que estão calcadas na qualidade como soma das propriedades e características de um serviço, buscando atender a necessidades específicas e às expectativas demandadas pelos clientes ou usuários. Alvarado Peña (2010) destaca, ainda, que é difícil muitas vezes definir a questão da qualidade pois significado dos valores variam de acordo com a cultura organizacional da IES (VIEIRA, 2007).

Outro aspecto relevante na qualidade de serviços lembrado por Martín (1991;1992) é a dimensão pessoal na prestação do serviço, que envolvem os aspectos de relacionamento interpessoal, que por sua vez tem influência dos valores do indivíduo que presta o serviço. Desta forma, Plancarte (1998) afirma que para se ter qualidade no serviço é preciso qualificar os indivíduos, para que aceitem mudar e melhorar continuamente. Esse ponto é reforçado por Hernandez et. al. (2009) que destaca que dentre todos os componentes envolvidos na prestação de serviços, o mais crítico parece ser o fator humano.

Para a ação humana, os valores apresentam a seguinte caracterização segundo Garza (2004, p.49):

- Eles são bipolares: porque manifestam uma dupla polaridade: bom - ruim, beleza-feiura, útil-inútil, heroico-covarde;

- Eles são interdependentes: nas descrições que são feitas dos valores nós explicamos de forma independente, isto é, quando falamos sobre a verdade ou justiça, na vida real eles têm uma interdependência que nos faz pensar, por exemplo, a justiça deve ser verdadeira. É por isso que, na vida comum, interdependência significa decidir entre um valor e outro;

- Transcendência aos fatos: os valores são depositados em fatos, objetos e ações; Se ao olhar para uma pintura parece 
bonita, a beleza é independente da imagem que observamos e vai além dessa realidade concreto e específico;

- Eles exigem a sua realização: os valores existem por si mesmos, mas eles exigem atos humanos para sua realização; a verdade na ciência não existiria sem a pesquisa de pacientes dos pesquisadores.

Ainda, segundo Garza (2004) e Siqueira e Vieira (2012), todas essas características descrevem, para os valores através de fatos e ações que o homem realiza, uma maneira de entender a importância do termo a partir de diferentes abordagens em nossas vidas.

Para Rosini e Limongi-França (2013), para que se tenha a tão necessária qualidade na educação, e onde a mesma possa contribuir para a qualidade de vida das pessoas, são considerados os seguintes vetores: os professores, a escola, os alunos e as políticas empregadas nesse segmento, onde de uma forma mais detalhada pode-se dizer:

a) Professores: condições de trabalho aceitáveis, recebimento de melhores salários, maior quantidade de treinamentos, capacitações e desenvolvimento humano e profissional, maior incentivo ao desenvolvimento de pesquisas científicas, professores reconhecidos, valorizados e respeitados, maior acesso e ampliação do conhecimento, jornada de trabalho adequada para o efetivo exercício do magistério.

b) Escola: quanto aos recursos instrucionais de materiais didáticos, tão importantes quanto a sua utilização; maior valorização de seus recursos humanos, contando inclusive com o professor; disponibilização de melhor infraestrutura de campus e acesso a computadores e tecnologias de informação e comunicação de porte adequado.

c) Alunos: é preciso que estes leiam e produzam mais, realizando produções acadêmicas e práticas, a fim de que se possa criar uma cultura que valorize o saber, o conhecimento e a formação desse mesmo aluno; a qualidade da educação tende a possibilitar a formação de recursos humanos, habilitando-os profissionalmente, com compromisso pessoal, ser ético e estar apto à educação continuada, estando este preparado para sua evolução como cidadão; maior respeito e consideração aos professores. É preciso ainda que esse aluno tenha disciplina, compromisso e comprometimento com os estudos, com a educação e com sua vida. 
d) Políticas: é preciso que tenhamos maiores investimentos e verbas destinados à educação, desde os ensinos fundamental, infantil, médio (educação de base) ao superior, utilizando esses investimentos de forma adequada, controlando-os e avaliando-os de forma adequada e sustentável; lutar pelo fim definitivo da corrupção política no país; acesso amplo e restrito à internet, por intermédio da utilização de banda larga de comunicação.

Para Tsortis et. al. (2017), as IES possuem um papel fundamental na sustentabilidade, já que suas atividades, incluindo pesquisas, ensino e engajamento social são de extrema importância para um aprendizado de toda uma sociedade. Ainda para os autores, as Instituições têm um grande desafio a fim de encontrarem práticas e ações que englobem o tripé da sustentabilidade, ou seja, é necessário abordar as três esferas da sustentabilidade: social, ambiental e econômica.

Alvarado Peña (2010) propõe quatro dimensões para medir a qualidade de serviços em IES: qualidade no serviço, qualidade das relações humanas, qualidade das atitudes e qualidade na responsabilidade, conforme detalhado no Quadro 1 abaixo:

Quadro 1 - Dimensões da Qualidade de Serviços em IES

\begin{tabular}{|l|l|}
\hline Qualidade no serviço & $\begin{array}{l}\text { Acessibilidade ao serviço } \\
\text { Coordenação na prestação do serviço } \\
\text { Tempo de entrega de serviço }\end{array}$ \\
Tumanas & $\begin{array}{l}\text { Respeito ao usuário } \\
\text { Compromisso e lealdade com o usuário } \\
\text { Busca pela Excelência }\end{array}$ \\
Qualidade nas Atitudes & $\begin{array}{l}\text { Responsabilidade com o serviço } \\
\text { Tolerância e aceitação de sugestões } \\
\text { Cordialidade, ajuda e iniciativa no serviço } \\
\text { Cualidade em Responsa- } \\
\text { bilidade }\end{array}$ \\
\hline
\end{tabular}

Fonte: elaboração própria com base em Alvarado Peña (2010). 
Considerado o referencial exposto, observa-se que a qualidade em serviços em IES pode ser vista por diversos prismas, porém, ao mesmo tempo é clara que a influência dos valores, comportamentos e atitudes, perpassam essas visões e tem influência na atuação do pessoal técnico-administração e por consequência na qualidade do serviço prestado tanto ao docente como ao estudante da IES.

\section{Metodologia}

Para obter informações acerca dos valores organizacionais praticados pelos funcionários técnico-administrativos em sua atuação e as percepções dos estudantes e professores, dos serviços prestados por eles, empreendeu-se uma pesquisa de campo. Adotando-se como público estudantes, professores e funcionários técnico-administrativos de uma IES brasileira que aderiu ao estudo. O projeto de pesquisa elaborado foi cadastrado na Plataforma Brasil sob o número CAAE: 73335517.4.0000.5493 tendo sido aprovada pelo Comitê da Ética e Pesquisa (CEP) da IES participante pelo parecer No. 2.396.609 de 23 de novembro de 2017.

Foram elaborados dois questionários estruturados online, um para aplicação aos técnico-administrativos e outro para aplicação tanto para os estudantes, como para os professores, utilizando-se da ferramenta de formulários do Google. A base para a elaboração das questões foram as dimensões da qualidade de serviços em IES, definidas por Alvarado Peña (2010) e apresentadas no Quadro 1. A ferramenta foi escolhida para facilitar o acesso aos participantes, assim como, para obter melhor acurácia dos dados, que foram armazenados em banco de dados e posteriormente tabulados.

Para responder ao questionário, os sujeitos foram convidados pelos pesquisadores, com apoio das lideranças de cada setor da IES, bem como, das coordenações de curso. Para garantir a aleatoriedade definida para a amostra, em nenhum momento houve qualquer identificação os sujeitos. A pesquisa foi aplicada no período de 30/01/2018 a 13/03/2018.

Adotou-se como critérios de inclusão: 1) o aceite da IES em participar da pesquisa; 2) o participante estar vinculado à IES participante; e 3) o aceite do participante por meio de sua concordância com o Termo de Consentimento Livre e Esclarecido (TCLE) 
que também foi disponibilizado online, como critério de exclusão adotou-se a perda do vínculo do participante com a IES durante o período de coleta de dados.

Ambos os questionário foram estruturados em quatro partes. A primeira dispunha de duas questões, uma relacionada ao aceite Termo de Consentimento Livre e Esclarecido (TCLE) e outra com espaço para deixar o e-mail caso desejasse receber os resultados da pesquisa. Na segunda parte, foram dispostas questões específicas para caracterização dos respondentes, como IES onde atuam, sexo, idade, curso ou programa ao qual está vinculado, dentre outras, destacando-se que, em nenhum momento houve a identificação do sujeito ou da IES, preservando seu anonimato. Nessas questões, foram utilizadas escalas nominais, que segundo Marconi e Lakatos (2002) visam a transformar fatos qualitativos em quantitativos ou variáveis para serem mensuradas, no caso da escala nominal em categorias específicas.

Na terceira parte, no questionário do corpo técnico administrativo buscou-se captar sua percepção quanto sua atuação e o serviço prestado, enquanto no questionário dos professores e estudantes, a percepção quanto ao serviço prestado pelo pessoal técnico administrativo. Em ambos, foram dispostas 25 afirmações, em que o respondente, escolhia em que frequência estava presente a situação, por meio da escala Likert, escolhia entre: 1 - Nunca; 2 - Raramente;3 - Algumas vezes; 4 - Frequentemente; 5 - Sempre. Na quarta e última parte do questionário, deixou-se um espaço livre para que o respondente pudesse deixar suas críticas e sugestões.

Para as análises estatísticas, utilizou-se o software IBM SPSS Estatistics v.25, incialmente foi testada a confiabilidade dos instrumentos, com base nas amostras, especificamente nas questões que usaram Likert, que possuem a mesma escala, utilizou-se o coeficiente alfa de Cronbach, que segundo Malhotra (2008) mede a consistência interna entre os itens que constituem a escala de respostas em um questionário. $\mathrm{O}$ coeficiente pode variar de 0 a 1 ; quanto mais próximo de 1 , indica maior confiabilidade; e é considerado como satisfatório acima de 0,6. Com base nas respostas obtidas, obteve-se o valor de 0,852 para o alfa de Cronbach no questionário do corpo técnico administrativo, de 0,957 no de estudantes e 0,928 no dos 
professores, que indica uma alta confiabilidade, para todos os casos, sendo as amostras válidas e sem vieses.

Na verificação das hipóteses das questões, aplicou-se o teste do qui-quadrado que, segundo Larson e Faber (2010), é utilizado para testar se uma distribuição de frequência se encaixa em uma distribuição esperada. Nesse caso, compara-se a frequência obtida na amostra com uma suposta distribuição de frequência específica, hipotética.

No teste realizado, obteve-se, no questionário do corpo técnico-administrativo, das 25 questões testadas, 24 apresentam distribuição compatível com o esperado, ou seja, as respostas ocorrem com probabilidades iguais. A única questão em que isso não ocorreu, foi a questão que trata da exposição dos sentimentos (questão no. 17), que indica neste caso, em um nível de significância de $5 \%$ que não é possível afirmar a uniformidade da distribuição das respostas dessa questão.

No questionário dos estudantes, das 25 questões testadas, 23 apresentam distribuição compatível com o esperado, já na questão que trata de tratamento injusto (questão no. 1) e na questão sobre más experiências com serviço prestado (questão no. 2) não houve uniformidade na distribuição.

Enquanto no questionário dos professores, das 25 questões testadas, 23 apresentam distribuição compatível com o esperado, já na questão que trata da celeridade no atendimento das solicitações (questão no. 19) e na que trata da excelência do serviço prestado (questão no. 23), não houve uniformidade na distribuição.

As questões em que não houve uniformidade de distribuição, em um nível de significância de 5\%, não inviabilizaram as análises propostas e os objetivos da pesquisa e serão demonstradas posteriormente, uma vez que foram analisadas de forma integrada com as demais, buscando uma análise quantitativa e qualitativa, que segundo Minayo (2002), permite o entendimento dos meandros da realidade estudada, com suas crenças e valores.

\section{Apresentação e análise dos resultados}

A pesquisa contou ao todo com 223 respondentes válidos, sendo 95 estudantes (43\%), 57 professores (25\%) e 71 funcionários (32\%) pertencentes ao corpo técnico-administrativo, houve ainda 6 
respondentes que abandonaram ao preenchimento do questionário e foram desconsiderados para as análises.

Com relação à caracterização dos respondentes, 56\% são do sexo feminino e $44 \%$ do sexo masculino, pode-se verificar, ainda, em função das faixas etárias (Tabela 1), que a maioria dos respondentes tem até 40 anos e $84 \%$ tem até 50 anos.

Tabela 1 - Distribuição por Faixa Etária

\begin{tabular}{l|l|l}
\hline Faixa Etária(anos) & Respondentes N=223 & $\%$ \\
\hline 18 a 30 & 69 & 31 \\
\hline 31 a 40 & 64 & 29 \\
\hline 41 a 50 & 54 & 24 \\
\hline 51 a 60 & 23 & 10 \\
\hline Mais que 60 & 13 & 6 \\
\hline
\end{tabular}

Fonte: dados da pesquisa.

Analisando o tempo de vinculação com a IES dos professores e técnico-administrativos, verificou-se que a maioria $(69 \%)$ tem até 5 anos de tempo de casa, como pode ser observar na Tabela 2.

Tabela 2 - Vínculo com a IES

\begin{tabular}{l|l|l}
\hline Tempo de Casa (anos) & Respondentes N=128 & $\%$ \\
\hline até 3 & 48 & $38 \%$ \\
\hline entre 3 e 5 & 40 & $31 \%$ \\
\hline entre 5 e 10 & 26 & $20 \%$ \\
\hline entre 10 e 20 & 12 & $9 \%$ \\
\hline acima de 20 & 2 & $2 \%$ \\
\hline \multicolumn{2}{l}{ Fonte: dados da pesquisa. } \\
\hline
\end{tabular}

Considerando que idade e tempo de casa podem ser variáveis importantes na cultura organizacional e consequentemente nos valores cultivados por esses indivíduos, chama a atenção que cerca de um terço da amostra estudada tenha até 30 anos e ao mesmo tempo 
o contingente de professores e técnico administrativo ao mesmo tempo tenha até 3 anos de trabalho na Instituição.

Analisando as respostas dos estudantes sobre os serviços prestados verificou-se que $35 \%$ dos respondentes afirmam que tratamento injusto ou indiferente caracteriza o pessoal administrativo da instituição de forma frequente ou sempre, enquanto $40 \%$ afirmou ter tido más experiências com o serviço prestado pelo pessoal administrativo de forma frequente ou sempre. Por outro lado, quando questionados sobre utilizar os serviços prestados pelo pessoal administrativo, 60\% utilizam os serviços raramente ou algumas vezes, enquanto $11 \%$ afirmaram nunca utilizar os serviços. Essas informações denotam de forma geral que apesar de se utilizarem dos serviços de forma não frequente, quando estes são necessários as experiências são negativas.

A Tabela 3 a seguir apresenta uma síntese das principais questões que retratam a percepção dos estudantes quanto ao serviço prestado pelo pessoal administrativo da IES estudada.

\section{Tabela 3 - Percepção dos Estudantes}

\begin{tabular}{l|l|l|l|l|l|l|l}
\hline Afirmação / Respostas (N=95) & 1 & 2 & 3 & 4 & 5 & NFQ & FQ \\
\hline $\begin{array}{l}\text { Os usuários têm acesso aos serviços pres- } \\
\text { tados pelo pessoal administrativo desta } \\
\text { instituição. }\end{array}$ & 17 & 28 & 25 & 19 & 6 & $74 \%$ & $26 \%$ \\
\hline $\begin{array}{l}\text { Há um grau de coordenação interna e ex- } \\
\text { terna nos serviços prestados pelo pessoal } \\
\text { administrativo. }\end{array}$ & 28 & 23 & 27 & 11 & 6 & $82 \%$ & $18 \%$ \\
\hline $\begin{array}{l}\text { Tive a oportunidade de ser atendido de } \\
\text { forma rápida pelo pessoal administrativo } \\
\text { desta instituição. }\end{array}$ & 51 & 21 & 12 & 7 & 4 & $88 \%$ & $12 \%$ \\
\hline $\begin{array}{l}\text { Há um grande espaço de tempo entre a } \\
\text { realização de uma solicitação e o atendi- } \\
\text { mento ou resposta recebida por parte do } \\
\text { pessoal administrativo desta instituição. }\end{array}$ & 12 & 18 & 15 & 17 & 33 & $47 \%$ & $53 \%$ \\
\hline $\begin{array}{l}\text { A prestação do serviço se dá com respei- } \\
\text { to diante das necessidades do usuário. }\end{array}$ & 24 & 28 & 25 & 12 & 6 & $81 \%$ & $19 \%$ \\
\hline
\end{tabular}




\begin{tabular}{l|l|l|l|l|l|l|l}
\hline Afirmação / Respostas (N=95) & 1 & 2 & 3 & 4 & 5 & NFQ & FQ \\
\hline $\begin{array}{l}\text { O pessoal administrativo expressa senti- } \\
\text { do de lealdade para com o serviço pres- } \\
\text { tado. }\end{array}$ & 27 & 33 & 18 & 11 & 6 & $82 \%$ & $18 \%$ \\
\hline $\begin{array}{l}\text { O pessoal administrativo se esforça conti- } \\
\text { nuamente para melhorar os serviços que } \\
\text { prestam. }\end{array}$ & 33 & 20 & 28 & 9 & 5 & $85 \%$ & $15 \%$ \\
\hline $\begin{array}{l}\text { O pessoal administrativo costuma cum- } \\
\text { prir efetivamente as responsabilidades } \\
\text { que lhes correspondem. }\end{array}$ & 22 & 32 & 26 & 9 & 6 & $84 \%$ & $16 \%$ \\
\hline $\begin{array}{l}\text { O pessoal administrativo tem uma atitu- } \\
\text { de de aprovação das sugestões e críticas } \\
\text { recebidas pelo usuário acerca do serviço } \\
\text { prestado. }\end{array}$ & 30 & 26 & 26 & 8 & 5 & $86 \%$ & $14 \%$ \\
\hline $\begin{array}{l}\text { Os usuários recebem uma atenção cordial } \\
\text { por parte do pessoal administrativo desta } \\
\text { instituição. }\end{array}$ & 18 & 35 & 23 & 15 & 4 & $80 \%$ & $20 \%$ \\
\hline $\begin{array}{l}\text { O pessoal administrativo busca preparar- } \\
\text { se para prestar um melhor serviço. }\end{array}$ & 32 & 26 & 22 & 10 & 5 & $84 \%$ & $16 \%$ \\
\hline $\begin{array}{l}\text { O pessoal administrativo costuma anteci- } \\
\text { par-se estrategicamente para as funções e } \\
\text { serviços prestados. }\end{array}$ & 35 & 27 & 22 & 5 & 6 & $88 \%$ & $12 \%$ \\
\hline
\end{tabular}

Fonte: dados da pesquisa.

1 - Nunca; 2 - Raramente; 3 - Algumas vezes; 4 - Frequentemente;

5- Sempre.

NFQ - Não frequente; FQ - Frequente.

É possível notar pelas informações apresentadas que de maneira geral os estudantes não percebem a presença dos valores e atitudes, que caracterizariam uma boa qualidade na prestação dos serviços da IES, considerando altos percentuais de Não Frequência (NFQ - respostas 1 a 3) entre $74 \%$ e $88 \%$ e baixos percentuais de Frequência (FQ - respostas 4 e 5). Cumpre esclarecer que no que tange ao tempo relacionado ao serviço prestado, há uma percepção de frequente demora para ser atendido, porém, o mesmo não ocorre com relação à realização do serviço em si, onde os percentuais de NFQ e FQ, com $47 \%$ e $53 \%$, respectivamente mostram equilíbrio tendendo também à demora. 
Analisando as respostas dos docentes sobre os serviços prestados verificou-se $98 \%$, ou seja, 56 de 57 pesquisados, afirmam que tratamento injusto ou indiferente não ocorre de forma frequente e $53 \%$ afirmam que nunca houve esse tipo de conduta. Ao mesmo tempo, com $98 \%$ dos pesquisados também afirmam não constatar de forma frequente má experiência, sendo que $60 \%$ relatam nunca ter tido esta situação.

A Tabela 4 a seguir apresenta uma síntese das principais questões que retratam a percepção dos docentes quanto ao serviço prestado pelo pessoal administrativo da IES estudada.

\section{Tabela 4 - Percepção dos Docentes}

\begin{tabular}{l|l|l|l|l|l|l|l}
\hline Afirmação / Respostas (N=57) & 1 & 2 & 3 & 4 & 5 & NFQ & FQ \\
\hline $\begin{array}{l}\text { Os usuários têm acesso aos serviços pres- } \\
\text { tados pelo pessoal administrativo desta } \\
\text { instituição. }\end{array}$ & 2 & 5 & 9 & 25 & 16 & $28 \%$ & $72 \%$ \\
\hline $\begin{array}{l}\text { Há um grau de coordenação interna e ex- } \\
\text { terna nos serviços prestados pelo pessoal } \\
\text { administrativo. }\end{array}$ & 0 & 4 & 9 & 29 & 15 & $23 \%$ & $77 \%$ \\
\hline $\begin{array}{l}\text { Tive a oportunidade de ser atendido de } \\
\text { forma rápida pelo pessoal administrativo } \\
\text { desta instituição. }\end{array}$ & 4 & 6 & 9 & 19 & 19 & $33 \%$ & $67 \%$ \\
\hline $\begin{array}{l}\text { Há um grande espaço de tempo entre a } \\
\text { realização de uma solicitação e o atendi- } \\
\text { mento ou resposta recebida por parte do } \\
\text { pessoal administrativo desta instituição. }\end{array}$ & 7 & 27 & 12 & 9 & 2 & $81 \%$ & $19 \%$ \\
\hline $\begin{array}{l}\text { A prestação do serviço se dá com respeito } \\
\text { diante das necessidades do usuário. }\end{array}$ & 0 & 3 & 10 & 23 & 21 & $23 \%$ & $77 \%$ \\
\hline $\begin{array}{l}\text { O pessoal administrativo expressa sentido } \\
\text { de lealdade para com o serviço prestado. }\end{array}$ & 1 & 4 & 8 & 26 & 18 & $23 \%$ & $77 \%$ \\
\hline $\begin{array}{l}\text { O pessoal administrativo se esforça conti- } \\
\text { nuamente para melhorar os serviços que } \\
\text { prestam. }\end{array}$ & 1 & 3 & 17 & 17 & 19 & $37 \%$ & $63 \%$ \\
\hline
\end{tabular}




\begin{tabular}{l|l|l|l|l|l|l|l}
\hline Afirmação / Respostas (N=57) & 1 & 2 & 3 & 4 & 5 & NFQ & FQ \\
\hline $\begin{array}{l}\text { O pessoal administrativo costuma cumprir } \\
\text { efetivamente as responsabilidades que } \\
\text { lhes correspondem. }\end{array}$ & 0 & 3 & 16 & 16 & 22 & $33 \%$ & $67 \%$ \\
\hline $\begin{array}{l}\text { O pessoal administrativo tem uma atitu- } \\
\text { de de aprovação das sugestões e críticas } \\
\text { recebidas pelo usuário acerca do serviço } \\
\text { prestado. }\end{array}$ & 2 & 7 & 14 & 24 & 10 & $40 \%$ & $60 \%$ \\
\hline $\begin{array}{l}\text { Os usuários recebem uma atenção cordial } \\
\text { por parte do pessoal administrativo desta } \\
\text { instituição. }\end{array}$ & 3 & 3 & 15 & 20 & 16 & $37 \%$ & $63 \%$ \\
\hline $\begin{array}{l}\text { O pessoal administrativo busca preparar- } \\
\text { se para prestar um melhor serviço. }\end{array}$ & 1 & 5 & 15 & 20 & 16 & $37 \%$ & $63 \%$ \\
\hline $\begin{array}{l}\text { O pessoal administrativo costuma anteci- } \\
\text { par-se estrategicamente para as funções e } \\
\text { serviços prestados. }\end{array}$ & 3 & 8 & 15 & 24 & 7 & $46 \%$ & $54 \%$ \\
\hline
\end{tabular}

Fonte: dados da pesquisa.

1 - Nunca; 2 - Raramente; 3 - Algumas vezes; 4 - Frequentemente; 5- Sempre.

NFQ - Não frequente; FQ - Frequente.

De acordo com as informações da Tabela 4, de forma geral há uma percepção positiva por parte dos docentes pesquisados com relação aos serviços prestados tendo em vista uma média FQ acima de $67 \%$. Como ponto de atenção verifica-se a questão da antecipação às necessidades com FQ em $54 \%$ e a questão relacionada à críticas e sugestões.

Percebe-se nas análises apresentadas que as respostas dos estudantes são bem diferentes das colhidas dos professores. Isso se deve, talvez, por conta da periodicidade de solicitações de serviços que os alunos utilizam, enquanto $60 \%$ dos estudantes utilizam de forma não frequente (NFQ), 63\% dos docentes utilizam de forma frequente (FQ).

A Tabela 5 a seguir apresenta uma síntese das principais questões que retratam a percepção do corpo técnico-administrativo quanto ao serviço prestado e os valores presentes em sua atuação. 
Tabela 5 - Percepção do Corpo Técnico-Administrativo

\begin{tabular}{l|l|l|l|l|l|l|l}
\hline Afirmação / Respostas (N=71) & 1 & 2 & 3 & 4 & 5 & NFQ & FQ \\
\hline $\begin{array}{l}\text { Busco aperfeiçoar-me para me superar } \\
\text { nas atividades que realizo. }\end{array}$ & 0 & 0 & 0 & 11 & 60 & $0 \%$ & $100 \%$ \\
\hline $\begin{array}{l}\text { Trato com respeito todas as pessoas que } \\
\text { se dirigem a mim. }\end{array}$ & 0 & 0 & 0 & 8 & 63 & $0 \%$ & $100 \%$ \\
\hline $\begin{array}{l}\text { Escutar com paciência as solicitações dos } \\
\text { usuários é parte do meu trabalho. }\end{array}$ & 0 & 0 & 1 & 10 & 60 & $1 \%$ & $99 \%$ \\
\hline $\begin{array}{l}\text { Participo de maneira voluntária em } \\
\text { atividades para alcançar os objetivos da } \\
\text { Instituição. }\end{array}$ & 0 & 2 & 9 & 24 & 36 & $15 \%$ & $85 \%$ \\
\hline $\begin{array}{l}\text { Os interesses coletivos são o norte so- } \\
\text { bre o qual estão orientadas as ações que } \\
\text { realizo. }\end{array}$ & 1 & 1 & 4 & 18 & 47 & $8 \%$ & $92 \%$ \\
\hline $\begin{array}{l}\text { Busco tratar com imparcialidade os } \\
\text { assuntos e procedimentos dos quais faço } \\
\text { parte. }\end{array}$ & 1 & 1 & 4 & 12 & 53 & $8 \%$ & $92 \%$ \\
\hline $\begin{array}{l}\text { Considero importante expressar as mi- } \\
\text { nhas opiniões em todas as situações que } \\
\text { sejam necessárias. }\end{array}$ & 0 & 4 & 12 & 25 & 30 & $23 \%$ & $77 \%$ \\
\hline $\begin{array}{l}\text { Deixo conhecer os verdadeiros sentimen- } \\
\text { tos, mesmo que isso signifique confronto } \\
\text { com os outros. }\end{array}$ & 8 & 15 & 22 & 13 & 13 & $63 \%$ & $37 \%$ \\
\hline $\begin{array}{l}\text { Contribuo para o avanço dos aspectos } \\
\text { éticos e morais do ambiente institucional. }\end{array}$ & 0 & 0 & 7 & 15 & 49 & $10 \%$ & $90 \%$ \\
\hline $\begin{array}{l}\text { Os interesses coletivos e institucionais de- } \\
\text { vem estar acima dos interesses particulares. }\end{array}$ & 1 & 0 & 14 & 27 & 29 & $21 \%$ & $79 \%$ \\
\hline $\begin{array}{l}\text { Esforço-me para alcançar a eficiência ad- } \\
\text { ministrativa sem esquecer o projeto social } \\
\text { e humano da Instituição. }\end{array}$ & 0 & 0 & 4 & 16 & 51 & $6 \%$ & $94 \%$ \\
\hline $\begin{array}{l}\text { Tomo decisões que contribuam para os } \\
\text { valores da comunidade universitária. }\end{array}$ & 0 & 2 & 6 & 20 & 43 & $11 \%$ & $89 \%$ \\
\hline Fonte: dados da pesusa & & & & & & & \\
\hline
\end{tabular}

Fonte: dados da pesquisa.

1 - Nunca; 2 - Raramente; 3 - Algumas vezes; 4 - Frequentemente; 5-

Sempre.

NFQ - Não frequente; FQ - Frequente. 
As informações apresentadas, mostram de forma geral, uma percepção positiva por parte do pessoal administrativo quando ao serviço que prestam, assim como, a presença de valores que caracterizariam uma boa qualidade do serviço. Cabe destacar que que boa parte dos entrevistados não deixa conhecer seus verdadeiros sentimentos, isso pode indicar profissionalismo e imparcialidade, porém, pode também indicar que a expressão de sentimentos é reprimida de alguma forma. Verifica-se, assim, que a percepção que pessoal administrativo tem do trabalho que realiza e dos valores presentes em sua atuação não está em sintonia com que pensam especificamente os estudantes da IES.

Diante das informações coletadas dos estudantes, docentes e pessoal administrativo, pode-se verificar uma grande disparidade entre as percepções de forma até antagônica dos serviços prestados pelo pessoal técnico administrativo entre estudantes e docentes, assim como, a percepção que o pessoal técnico administrativo tem de sua atuação. Um dos pontos já citados diz respeito à frequência de utilização do serviço, porém, um outro fator de influência pode ser a hierarquização presente nas IES, em que ao estudante cabe disciplina e obediência às regras, mesmo havendo as instâncias de participação o estudante se sente alijado das decisões que ocorrem na IES, Malavasi (2010, p.92) traz uma reflexão importante que ocorre na escola e vem sendo também trazida à IES: “Hoje temos alunos que se portam como verdadeiros inimigos da escola e de todas as pessoas que lá trabalham".

Neste sentido, o docente, em grau de hierarquia mais elevado que o estudante, mesmo que de maneira informal, pode ter tratamento diferenciado e, portanto, um melhor serviço do que aquele prestado ao estudante. $\mathrm{O}$ antagonismo do estudante aos demais entes da IES pode fazer com que em um momento como esses, de responder a uma pesquisa, pode deixar aflorar toda carga de negatividade em seu tratamento por parte da IES, o que não pode ser minimizado ou menosprezado, mas que merece atenção a aprofundamento, uma vez que também ficou constatado que a utilização dos serviços não é frequente, mas quando ocorre a experiência em geral é negativa. 


\section{CONSIDERAÇõES FINAIS}

Como discutido, essa pesquisa teve como objetivo analisar os valores organizacionais presentes na atuação do pessoal técnico-administrativo, como determinantes na qualidade do serviço prestado ao estudante e ao professor em IES, verificando os principais aspectos da cultura organizacional nas IES.

Há de se ressaltar que os respondentes pertencem a apenas uma IES, assim, acredita-se que essa escala possa ser melhor validada, na aplicação a outras instituições de ensino, podendo assim serem analisados outros cenários, contribuindo ainda mais para essa escala e modelo de investigação.

Os valores obtidos para o coeficiente alfa de Cronbach de 0,852 para o corpo técnico administrativo, de 0,957 para os estudantes e 0,928 para os professores, indicam alta confiabilidade, para todos os casos, considerando dessa maneira, as amostras válidas e sem vieses.

Já na verificação das hipóteses das questões, o resultado dos testes do qui-quadrado que, trazem no questionário do corpo técnico-administrativo, das 25 questões testadas, 24 apresentam distribuição compatível com o esperado. Quanto ao questionário dos estudantes, das 25 questões testadas, 23 apresentam distribuição compatível com o esperado.

E em relação ao questionário dos professores, das 25 questões testadas, 23 apresentam distribuição compatível com o esperado. Dessa maneira, o grau de confiança dos questionários apresentou resultado bastante elevado.

A maioria dos respondentes da pesquisa são do sexo feminino (56\%) e a maior parte apresenta faixa etária entre 18 a 30 anos (31\%).

Quanto ao tempo de vinculação com a IES dos professores e técnico-administrativos, a maioria deles (69\%) tem até 5 anos de tempo de casa.

\section{Em relação aos estudantes}

Percebe-se na análise das respostas dos estudantes sobre os serviços prestados verificou-se que muitos deles afirmam que o tratamento injusto ou indiferente caracteriza o pessoal administrativo da instituição de forma frequente ou sempre, enquanto boa parte deles afirmou ter tido más experiências com o serviço prestado pelo 
pessoal administrativo de forma frequente. Já em relação a utilização dos serviços prestados pelo pessoal administrativo, grande parte deles utilizam os serviços raramente ou algumas vezes.

A conclusão que se chegou é que de forma geral em relação aos serviços, quando estes são necessários as experiências são negativas.

De maneira geral os estudantes não percebem a presença dos valores e atitudes, que caracterizariam uma boa qualidade na prestação dos serviços da IES. Já em relação ao tempo relacionado ao serviço prestado, há uma percepção de frequente demora para ser atendido.

\section{Quanto aos docentes}

Analisando as respostas dos docentes sobre os serviços prestados verificou-se que quase a totalidade dos pesquisados, afirmam que o tratamento injusto ou indiferente não ocorre de forma frequente e outra parte que nunca houve esse tipo de conduta. A maioria ainda afirma não constatar de forma frequente má experiência.

Destacam-se ainda que os usuários têm acesso aos serviços prestados pelo pessoal administrativo da instituição, e que há um grande espaço de tempo entre a realização de uma solicitação e o atendimento ou resposta recebida por parte do pessoal administrativo desta instituição. Porém, nem todo o pessoal administrativo se esforça continuamente para melhorar os serviços que prestam e não costuma cumprir efetivamente as responsabilidades que lhes correspondem.

Percebe-se ainda que as análises apresentadas pelos estudantes são bem diferentes das colhidas dos professores.

\section{Quanto ao corpo técnico-administrativo}

O corpo técnico-administrativo que respondeu a pesquisa procurou aperfeiçoar-se para superar as atividades que realiza. Os respondentes dizem tratar com respeito as pessoas que se dirigem a eles. Os mesmos, escutam com paciência as solicitações das pessoas que fazem parte do seu trabalho.

As informações apresentadas, mostram uma percepção positiva por parte da equipe administrativa quando ao serviço que prestam, assim como, a presença de valores que caracterizariam uma boa qualidade do serviço. 
Verificou-se, porém, grande disparidade entre as percepções dos serviços prestados pelo pessoal técnico administrativo entre estudantes e docentes, assim como, a percepção que o pessoal técnico administrativo tem de sua atuação. Em um dos pontos visto diz respeito que ao estudante cabe disciplina e obediência às regras, mesmo havendo as instâncias de participação o estudante se sente alijado das decisões que ocorrem na IES.

Os resultados apresentados reforçam a importância das IES formularem estratégias que propiciem a absorção dos valores organizacionais por parte do corpo técnico-administrativo, de forma a promover melhorias na qualidade dos serviços prestados e reduzir a disparidade entre as percepções por parte de docentes e estudantes. As informações apresentadas, permitem ainda, aprofundamento em questões específicas, bem como, aplicação em outras realidades e ser alvo de estudos comparativos futuros.

\section{REFERÊNCIAS}

ALVARADO PEÑA, Lisandro J. Calidad de servicio en Universidades Públicas Venezolanas. TEACs. Caracas, ano 2, n.4, p. 45-58, jun. 2010.

ALVARADO PEÑA, Lisandro J. Reflexiones teóricas: valores éticos en la prestación de servicios de la administración pública. Gestión y Gerencia. Caracas, v. 5, n.2, p. 31-58, ago. 2011.

CAMARASA, Juan. La Calidad en la Administración Pública. Educar en el 2000. Murcia, Espanha, n.9, p. 9-20. abr. 2004.

CASTELLS, Manuel; CARDOSO, Gustavo. (Orgs.) The Network Society: From Knowledge to Policy. Washington, DC: Johns Hopkins Center for Transatlantic Relations, 2005.

DIAS SOBRINHO, José. Democratização, qualidade e crise da Educação Superior: faces da exclusão e limites da inclusão. Educação e Sociedade. Campinas, v. 31, n. 113, p. 1223-1245, out.-dez. 2010.

FREITAS, Maria E. Cultura organizacional grandes temas em debate. Revista de Administração de Empresas, São Paulo, v. 3, n. 31, p. 73-82, jul.-set. 1991.

GARZA T., Juan Gerardo.Valores para el ejercicio profesional. Guías didáctica. Tecnológico de Monterrey.Mc Graw Hill, Talleres Digital Oriente S.A. de C.V., México DF, 2004.

HERNÁNDEZ, Judith; CHUMACEIRO, Ana; ATENCIO, Edith. (2009). Calidad de Servicio y Recurso Humano: caso estudio tienda por departamentos. Revista Venezolana de Gerencia. Maracaibo, ano 14, n. 47. jul-set. 2009.

HOFSTEDE, G. Culture and organizations: software of the mind. New York: McGraw-Hill, 1991. 
LARSON, Ron; FABER, Betsy. Estatística Aplicada. São Paulo: Pearson Prentice Hall, 2010.

MALAVASI, Maria Márcia S. Avaliação Institucional potencializada pela participação dos vários segmentos da escola. In: DALBEN, Ângela I. L. de F. et. al. Convergências e Tensões no campo da formação e do trabalho docente. Belo Horizonte: Autêntica, 2010. p. 84-103.

MALHOTRA, Naresh K. Pesquisa de Marketing: uma orientação aplicada. 4.ed. Porto Alegre: Bookman, 2008.

MARTÍN, William B. Servicios de calidad al cliente. México: Trillas, 1991.

MARTÍN, William B. Dirección de los servicios de calidad al cliente. México: Grupo Editorial Iberoamericana. 1992.

MINAYO, M. C. S. Pesquisa Social: teoria, método e criatividade. 20.ed. Rio de Janeiro: Vozes, 2002.

PLANCARTE, Rodrigo. El Servicio como Poder de Cambio. La característica distintiva en los negocios. Monterrey, Nuevo León-México: Ediciones Castillo, 1998.

ROSINI, Alessandro Marco; LIMONGI-FRANÇA, Ana Cristina. Quality indicators for technology mediated education (ICT). A discussion about organisational and technological networks in Brazil. Int. J. Education Economics and Development. Vol. 4, No. 1, pp.72-88. 2013.

SIQUEIRA, D. M.; VIEIRA, A. M. Valores organizacionais: percepção e legitimação. Revista Gestão \& Tecnologia, v. 12, n. 2, p. 168-191, 2012.

TZORTIS, Patrícia Storopoli; KNIESS, Claudia Terezinha; LOPES, Evandro Luiz; FERREIRA, Ana Paula do Nascimento Lamano; GOMES JUNIOR, José Carmino. A study of the environmental level of awareness among Business administration students in São Paulo, Brazil. RISUS - Journal on Innovation and Sustainability. Vol. 8, N. 4. 2017.

VARGAS, Martha E. Q.; ALDANA, Luzángela de V. Calidad y Servicio. Conceptos y herramientas. Bogota, Colombia: Universidad de la Sabana Ediciones (ECOE), 2007.

VIEIRA, A. M. Cultura organizacional em instituições de ensino: mapeamento e análise descritivo-interpretativa da produção acadêmica (1990-2005). 2007. 237f. Tese (Doutorado em Educação) - Universidade Estadual Paulista (UNESP), Marília, 2007.

Recebido em: 2-8-2019

Aprovado em: 14-11-2019

Avaliado pelo sistema double blind review.

Disponível em http://mjs.metodista.br/index.php/roc 